InterAção | 143

\title{
O EXERCÍCIO DO SOFT POWER: FUTEBOL E 0 CASO BRASILEIRO
}

\author{
Bruno Gomes Guimarães \\ Igor Amazarray** \\ Where politics, diplomacy and the business world have failed, \\ I believe that football can succeed. João Havelange ${ }^{1}$
}

Resumo

Com base no conceito de soft power, o artigo objetiva tratar do futebol como instrumento de poder estatal. $\mathrm{O}$ texto apresenta o futebol como um fator importante dentro do contexto internacional através principalmente de seu soft power e tem por objetivo mostrar que essa modalidade esportiva de fato funciona como instrumento estatal. Para demonstrar isso, o artigo analisa as ações do governo brasileiro envolvendo esse esporte, concluindo que o futebol é uma ferramenta primária, e não secundária, de soft power.

Palavras-chave: Relações Internacionais. Soft power. Esporte. Futebol.

\section{Abstract}

Based on the concept of soft power, this article aims to deal

\footnotetext{
* Graduando de Relações Internacionais pela UFRGS, bolsista de iniciação científica PIBIC/CNPq e Secretário-Geral do UFRGS Model United Nations 2011.

** Graduando de Relações Internacionais pela UFRGS.

1 apud BONIFACE, 2002, p. 9.
} 
with football as a source of State power. The text depicts football as an important factor in the international context mainly through its soft power, and its objective is to show that this sport actually works as an instrument of the state. In order to demonstrate this, the article analyses the Brazilian government's actions involving this sport, concluding that football is a soft power's primary source, and not secondary.

Keywords: International Relations. Soft power. Sport. Football.

\section{INTRODUÇÃO}

Tradicionalmente, o papel do esporte nos trabalhos da área de relações internacionais tem sido negligenciado (no mínimo subvalorizado) ou considerado irrelevante, ocupando um espaço marginal pela comunidade científica (ALLISON e MONNINGTON, 2002, p. 106-107; BECK, 2003, p. 389-391). Contudo, tendo em conta que os esportes estão presentes em todos os países do globo e que têm um alcance maior do que o da própria $\mathrm{ONU}^{2}$, esse suposto hábito de deixá-lo de lado em estudos internacionais deveria ser revisto.

Como Allison e Monnington (2002, p. 107) disseram: “(...) nós podemos notar que Estados utilizam o esporte de duas maneiras: para venderem-se e realçar suas imagens e para penalizar comportamentos internacionais que eles desaprovam.” (tradução nossa ${ }^{3}$ ). Além do mais, basta lembrar os nefastos jogos olímpicos de Berlim em

2 Por exemplo, em 2008 a ONU conta com somente 192 Estados-Membros, enquanto o Comitê Olímpico Internacional tem 205 países afiliados e a FIFA 208. 
InterAção | 145

1936 que serviram como propaganda dos nazistas (SHIRER, 1960; LARGE, 2007) e das Olimpíadas de Moscou de 1980 e de Los Angeles de 1984, que, devido à Guerra Fria, sofreram boicotes dos Estados Unidos e da União Soviética, respectivamente. Não só isso, mas o tema é bastante atual, levando autores como Singh (2006) e Nye (2008) a comentar sobre como as Olimpíadas de Pequim de 2008 serviram para aumentar o prestígio chinês tanto nacional quanto internacionalmente (e consequentemente seu soft power) ao mostrar a determinação de seu povo.

A atualidade do tema serviu como a principal inspiração para a elaboração do presente artigo. Este trabalho pretende ser um passo inicial ao estudo de como o esporte pode ser relevante para as Relações Internacionais, ao gerar recursos políticos úteis (ALLISON apud BECK, 2003, p. 390) e, mais especificamente, como o futebol, o esporte mais popular do mundo, serve de recurso de soft power.

Primeiramente será exposto o conceito de soft power - a habilidade de obter resultados desejados sem ter que forçar os outros através de ameaças ou pagamentos - de acordo com o que Nye, cunhador do termo, escreveu de 1990 até hoje. Também serão discutidos os meios para os Estados poderem exercê-lo, de acordo com Melissen (2005) e Nye (2004). Logo após, será mostrada a importância do futebol no mundo através de exemplos históricos, e, para finalizar, será feita uma análise das recentes ações governamentais brasileiras

3 (...) we can note that states have used sport in two principal ways: to sell themselves and enhance their image and to penalize international behaviour of which they disapprove. 
146 | InterAção

envolvendo o esporte para averiguar a presença de soft power no meio futebolístico.

\section{Soft power: Conceito, fontes e limitações}

Mesmo que o conceito de poder nas relações internacionais não seja totalmente consensual, em algum grau concorda-se que poder é a habilidade de obter os resultados desejados e stricto sensu a habilidade de influenciar os outros para obtê-los (NYE, 2004, p. 1-2). $\mathrm{Na}$ política internacional há três meios de realizar essa interação com os outros países: coerção, indução e cooptação, e a partir disso Nye (2004, p. 5) divide o poder em dois tipos: o hard power e o soft power, o primeiro sendo o poder de coagir e induzir, e o segundo o de cooptar. O hard power tem suas bases em ameaças e barganhas através dos poderes econômico e militar para fazer com que os Estados façam o que se deseja, enquanto o soft power consiste em fazer com que os outros países queiram a mesma coisa que se procura obter, ou seja, moldar as preferências dos outros conforme as suas.

Entretanto, Nye $(2004$, p. 6) ressalta que soft power não é somente influenciar - visto que influência também pode ser realizada através de hard power - e nem persuadir, mesmo que esses sejam aspectos importantes dele, mas é também atrair, e a atração leva muitas vezes à aquiescência. Nas palavras do autor:

se eu sou persuadido a seguir os seus objetivos sem qualquer ameaça ou troca acontecendo - em resumo, se meu comportamento é determinado por uma atração observável, porém intangível — o soft 
InterAção | 147

power está agindo. Soft power usa um tipo diferente de moeda (nem força, nem dinheiro) para engendrar cooperação: uma atração a valores em comum e à justiça e dever de contribuir para alcançar esses valores (NYE, 2004, p. 7, tradução nossa4).

Dessa forma, o soft power cria um ambiente propício para que os outros países desenvolvam preferências semelhantes ou então que tenham interesse em seguir os mesmos objetivos. As fontes de soft power de um país para criar esse ambiente são inúmeras, mas as principais, de acordo com Nye (2004, p. 11; 2006), são a cultura (em lugares onde ela é atrativa para os outros), os valores políticos (praticados tanto interna quanto internacionalmente) e a política externa (quando vista como legítima e havendo uma autoridade moral). Todavia, os valores políticos fazem parte da cultura nacional, e por isso usaremos apenas uma distinção entre cultura e políticas governamentais externas e internas.

A cultura de uma nação é uma fonte mais efetiva de soft power quando seus valores são bastante abrangentes e universais, pois possuem uma maior capacidade de atrair outras culturas - através de meios populares e de elite - ; porém, se a do outro país for muito rígida e tiver valores muito específicos, é improvável que a do primeiro consiga exercer qualquer atração. Um exemplo disso seria a cultura brasileira, mais especificamente o carnaval: enquanto essa festividade

4 If I am persuaded to go along with your purposes without any explicit threat or exchange taking place-in short, if my behavior is determined by an observable but intangible attraction - soft power is at work. Soft power uses a different type of currency (not force, not money) to engender cooperation - an attraction to shared values and the justness and duty of contributing to the achievement of those values. 
atrai pessoas no mundo todo em países ocidentais, em países árabes onde a cultura muçulmana é muito rígida e as mulheres devem cobrir seu corpo para sair em público, ela é vista como ofensiva e ultrajante e, portanto, não exerce atração alguma 5 .

A cultura de um país se difunde via comércio (cinema, marcas, literatura, culinária, arte, teatro) e intercâmbios culturais (inúmeros líderes de todo o mundo estudaram em universidades americanas, por exemplo). Importante ressaltar que não é apenas o governo que controla a difusão cultural e o seu soft power, mas as empresas multinacionais e indivíduos renomados também. Exemplos disso seriam a Microsoft para os EUA, a Adidas para a Alemanha e o Ronaldinho Gaúcho para o Brasil. Entretanto, nem sempre o soft power desses grupos pode ser acrescentado ao total do país, pois há a possibilidade de que faça o contrário do que se deseja e aja contra o soft power nacional (NYE, 2004, p. 17), como, por exemplo, as ações da Petrobrás na Bolívia em 2008.

Do mesmo modo, as políticas governamentais podem acrescentar ou diminuir o soft power de um país. Se aquilo que é praticado internamente, em questões tanto de valores políticos quanto de medidas mais concretas, for contrário ao que se prega internacionalmente, há diminuição de soft power. Portanto, o governo do país não pode ser hipócrita e deve manter uma política coesa em três esferas distintas: a interna, a bilateral e a multilateral. Um país pode conseguir mais soft power ao fazer regras, instituições internacionais e definir agen-

5 No entanto, se houvesse um movimento feminista pela liberdade das mulheres, talvez o carnaval as atraísse. É sempre uma questão de contexto. 
InterAção | 149

das multilaterais que pareçam legítimas aos olhos dos outros (NYE, 1990, p. 168; 2004, p. 10). Destarte ele estaria servindo de exemplo e poderia estar fazendo com que os outros quisessem o mesmo que ele - o soft power em ação.

Além dessas duas fontes principais, também há as fontes ligadas ao hard power. Muitas vezes, nações sentem-se atraídas a outras por causa de seu poderio militar ou econômico. É apostar no vencedor. Como disse Osama Bin Laden (apud NYE, 2004, p. 26): "quando as pessoas veem um cavalo forte e um cavalo fraco, por natureza, eles vão gostar do cavalo forte.” (tradução nossa ${ }^{6}$ ). Esse ponto leva Noya (2006) a criticar Nye por fazer uma teoria tão dualista, e chega a dizer que assim qualquer fonte legítima de poder produziria soft power (NOYA, 2006, p. 57). Contudo, Nye $(1990 ; 2004)$ deixa claro que apesar de haver um jogo entre os dois tipos de poder, cada um possui fontes primárias bem diferentes. Kennedy (2005, p. 1-2) também afirma que, ao contrário do que se pensa, os dois tipos de poder podem andar juntos sim, não sendo antitéticos ${ }^{7}$. Como disse Carr (apud MELISSEN, 2005, p. 2) "poder sobre a opinião não é menos essencial para propósitos políticos do que o poder econômico e militar, e sempre esteve associado com eles.” Então é notável a interação entre os dois tipos de poder, principalmente o papel do hard power como fonte secundária de

6 When people see a strong horse and a weak horse, by nature, they will like the strong horse.

70 autor também acredita que os dois tipos de poder estão se unificando, principalmente 0 americano. 
150 | InterAção

soft power.

Os efeitos dessas fontes são difusos, característica fundamental do soft power. Esse tipo de poder não é facilmente percebível em um só ponto, ele normalmente se encontra espalhado por toda a população de um determinado país. Desse fato se apreende que, para o soft power surtir mais efeitos, é necessário que o povo tenha voz na política, ao menos em parlamentos, e que governos deem atenção à opinião pública; democracias tendem a ser mais receptivas de soft power. Afinal "(...) soft power depende mais do que o bard power da existência de intérpretes e receptores de boa vontade." (NYE, 2004, p. 16, tradução nossa $\left.{ }^{8}\right)$.

Por causa dos efeitos difusos da atração gerada pela cultura e por políticas governamentais, é raro observar uma ação específica que tenha ocorrido por causa do soft power, com ele cria-se justamente uma influência geral e não um comando de ações determinadas — ele não gera obrigações. Tendo isso em mente, nota-se que o soft power produz mais frequentemente efeitos de longo prazo $^{9}$, e, justamente por causa disso, ele é mais efetivo em objetivos distantes no tempo e não muito específicos, tais como a defesa da democracia e dos direitos humanos, mas sempre lembrando que as situações variam; por sua vez, a efetividade em objetivos imediatos depende muito do contexto em que se encontra (NYE, 2004, p. 16-17).

8 (...) soft power depends more than hard power upon the existence of willing interpreters and receivers.

9 Efeitos mais diretos ocorrem mais esporadicamente, normalmente envolvendo a perda de soft power. 
InterAção | 151

\section{Exercendo soft power}

Ao contrário do hard power, o soft power não é uma ferramenta governamental tão facilmente utilizável para atingir resultados com uma rapidez considerável. Ameaças e barganhas têm um tempo de resposta muito menor do que o da atração. Outro motivo para que o soft power não seja facilmente exercido pelos governos é o fato de que poucas são as fontes que se podem manejar para conseguir resultados específicos - ele serve mais para moldar favoravelmente o ambiente em que ações são tomadas (NYE, 2004, p. 99).

Além das políticas específicas para cada situação, que dependem muito do contexto, um governo pode manter ou produzir soft power ao promover uma boa imagem de seu país, atraindo outras nações em aspectos gerais de sua cultura, sociedade e valores políticos. Melissen (2005, p. 19) distingue quatro métodos para que um país possa fazer isso: propaganda, o país como marca ${ }^{10}$, relações culturais em geral e diplomacia pública.

O primeiro método, a propaganda, deliberadamente procura dar uma informação que mude a opinião e os interesses dos receptores a favor daquele que a divulgou, tenta dizer o que eles devem pensar, estreitando as possibilidades de escolha de acordo com a vontade do propagandista (MELISSEN, 2005, p. 19-22). No passado, essa forma de atração foi amplamente utilizada, mas hoje um governo deve ter cuidado ao usá-la, porque "informação que pareça ser propa-

10 Nation branding, no original. 
ganda pode não apenas ser desdenhada, mas também pode se tornar contraprodutiva, se minar a reputação por credibilidade de um país." (NYE, 2004, p. 107, tradução nossa ${ }^{11}$ ). Por exemplo, as notícias que o governo americano divulgou sobre o Iraque de Saddam Hussein estar desenvolvendo armas de destruição em massa, que serviram de justificativa para a guerra de 2003, acabaram minando muito a credibilidade do país, visto que se mostraram infundadas.

Em segundo lugar, a divulgação de um país como marca é a venda da imagem do país no exterior, uma tentativa de mudar o olhar da opinião pública internacional ao projetar uma identidade que se destaque dos outros países (MELISSEN, 2005, p. 22-25). Na maioria das vezes, um dos principais objetivos desse método é criar mercados externos para produtos nacionais, e para isso deve haver uma ação conjunta do governo com empresas e outras organizações não governamentais. A construção de uma nova imagem, positiva para o país, já basta para aumentar o seu soft power.

Por sua vez, as relações culturais diferem dos outros três métodos, já que originalmente são tidas como uma voz não governamental nas relações internacionais dos países. Elas servem para difundir ideias e incentivar debates acerca das distintas realidades entre os povos, não estando diretamente ligada a políticas externas específicas. Apesar disso, as relações culturais vêm sendo apropriadas e/ ou fomentadas pelos governos, tornando difícil uma clara separação (MELISSEN, 2005, p. 25-27).

11 Information that appears to be propaganda may not only be scorned but also may turn out to be counterproductive if it undermines a country's reputation for credibility. 
O quarto e último método, a diplomacia pública, é tido por Melissen (2005, p. 3) como um instrumento-chave do soft power. Como diz o nome, esse tipo de diplomacia visa à opinião pública dos países estrangeiros, propagando uma imagem positiva do país e criando laços amistosos - o que gera mais soft power (NYE, 2004, p. 105-118). O que o diferencia dos outros métodos é o fato de que ele estabelece um diálogo com as sociedades civis dos outros países, não se confinando à transmissão de informações (como a propaganda), para manter boas relações entre Estados. A diplomacia pública complementa o método do país como marca ao conservar e ampliar as conexões culturais, assim sobrepondo-se às relações culturais como instrumento de soft power (MELISSEN, 2005, p. 19-27; NYE, 2004, p. 111). Nye (2004, p. 107-110) põe em evidência três dimensões da diplomacia pública que juntas formam uma imagem atrativa a favor do soft power: comunicação diária, que envolve explicar e expor o contexto das decisões de política externa e interna do dia-a-dia, estando sempre preparado para corrigir informações falsas que tenham sido divulgadas a seu respeito; comunicação estratégica, com eventos simbólicos e debates acerca de temas específicos para facilitar a aceitação de alguma política governamental em particular; e o desenvolvimento de relações duradouras com indivíduos-chave ao longo do tempo através de intercâmbios, conferências, treinamentos. $\mathrm{O}$ autor também ressalta que, para funcionarem, elas devem estar em sintonia com a postura internacional do país, já que não adianta dizer uma coisa e fazer outra, pois isso levaria a uma crise de credibilidade e faria o país perder soft power (NYE, 2004, p. 111).

Conforme Wang (2006, p. 35-40) a efetividade da diplo- 
macia pública varia conforme o objetivo procurado. Para ele, grupos subnacionais são os melhores para criar e manter um entendimento comum e cooperação mútua, e não o governo: para transmitir ideais e valores nacionais, o governo e tais grupos são igualmente relevantes. Contudo, em políticas governamentais e suas metas, grupos subnacionais não teriam muita importância. $\mathrm{O}$ autor também afirma que o governo deve servir mais amiúde como patrocinador, e os grupos mais como comunicadores e facilitadores (WANG, 2006, p. 40). Tanto ele quanto Melissen (2005, p. 29-30) lembram que o ideal é que o governo aja sempre em conjunto com os grupos subnacionais para a maior eficácia da diplomacia pública.

\section{Análise de caso}

Um estudo mais detalhado é necessário para uma melhor compreensão de como o futebol está ligado ao soft power. Por isso foi selecionado o caso brasileiro, notadamente no Haiti, focando nas políticas governamentais brasileiras envolvendo o esporte para consolidação do seu soft power.

\section{Brasil}

Com o governo de Lula, o Brasil buscou um papel maior no cenário internacional, procurando se firmar como potência regional e quiçá mundial. Para isso, foram fechadas parcerias com inúmeros países em desenvolvimento, e tomou-se papel mais ativo em questões de manutenção da paz mundial. O caso das forças de paz da ONU no 
InterAção | 155

Haiti (MINUSTAH), comandada pelo Brasil, é o caso mais evidente, e nele o papel do futebol foi de extrema importância (BIAZZI e FRANCESCHI NETO, 2007).

Desde que começou a intervenção militar em junho de 2004, com 1.200 soldados brasileiros, percebeu-se o papel que o futebol poderia desempenhar para legitimá-la. Logo de início, o exército do Brasil levou consigo não apenas armas e equipamentos militares, mas também mil bolas de futebol e camisas da seleção brasileira, para serem distribuídas em escolas haitianas.

Pouco tempo depois, o governo brasileiro propôs a ideia do "Jogo da Paz", entre a seleção brasileira e a haitiana, à Confederação Brasileira de Futebol (CBF) e aos jogadores. Todos prontamente aceitaram a proposta. Devido ao renome internacional dos jogadores brasileiros e da seleção canarinho, que então era a campeã do mundo, esse jogo seria um legitimador da intervenção da ONU e uma demonstração de comprometimento e respeito do Brasil para com a causa do Haiti (BIAZZI e FRANCESCHI NETO, 2007).

A partida foi realizada em agosto de 2004. Ela foi um claro ato de diplomacia pública através de comunicação estratégica entre o Estado Brasileiro e o povo haitiano. Ela serviu como aproximação entre os dois países e abrandou a intervenção militar que acontecia.

Como resultado disso a presença brasileira no Haiti seria mais bem vista e aceita por parte da população local o que de certa forma facilitaria o trabalho das Forças de Paz presentes, tornando-o mais ágil e eficaz e contribuindo para o alcance das metas, que são: contribuir para a segurança do país e estabelecer condições para uma transição política pacífica (BIAZZI e FRANCESCHI NETO, 2007). 
156 | InterAção

Nesse contexto, a política externa brasileira mostrou como uma iniciativa não-militar, ao usar de uma imagem agregadora, no caso, da seleção brasileira de futebol, pode colaborar com os propósitos do país, especificamente em uma missão de paz. As imagens da calorosa recepção do povo haitiano aos jogadores do Brasil a percorrer as ruas de Porto Príncipe em carros blindados a serviço da ONU ganharam o mundo através da mídia internacional e evidenciaram como um gesto simples pode se transformar num poderoso instrumento a favor da paz (AGUILAR, 2008, p. 7).

Ademais, o jogo também serviu para unir o povo do Haiti, que vinha sofrendo com o conflito civil. Antes de o jogo começar, o hino haitiano foi cantado em uníssono por mais de 15 mil pessoas, demonstrando todo o seu orgulho e patriotismo. A estabilização da situação no Haiti pôde, então, tornar-se mais fácil e rápida com a união dos cidadãos do país, que ocorreu devido ao futebol, instrumento do soft power brasileiro.

Nesse caso, viu-se o soft power brasileiro em ação no país e, além disso, aumentar em outros países, devido ao apelo internacional do esporte. Ele permitiu uma maior aproximação entre as tropas brasileiras e a população local. Isto facilita a consecução da operação de paz, até porque todas as tropas de outras nacionalidades usufruíram desse maior contato. Além do mais, o "Jogo da Paz" chamou a atenção internacional para a situação haitiana, o que pôde de certa forma fazer com que maiores esforços fossem realizados para a melhora da condição do país, inclusive para a "obtenção de recursos para desenvolvimento de projetos de construção da paz"(AGUILAR, 2008).

Além do caso do Haiti, o governo brasileiro, para firmar seu 
InterAção | 157

papel de potência, vem criando vínculos com países africanos, tornando-se um polo de atração. Para aumentar seu soft power no continente africano, o governo brasileiro criou parcerias com as confederações de futebol daqueles países para que seleções e times africanos treinassem em solo brasileiro, usufruindo de toda a infraestrutura disponível. Fora isso, o governo brasileiro também incentiva a ida de técnicos de futebol a times e seleções africanas. Esses são casos claros de diplomacia pública brasileira tentando criar vínculos bastante positivos com outros países: soft power.

Por fim, a própria realização da Copa do Mundo de futebol em 2014 é um grande ganho para o Brasil em questões de soft power. Já a partir do anúncio da FIFA de que o Brasil seria o país anfitrião do evento em outubro de 2007, as atenções se voltaram para o país. Desde então, o soft power brasileiro vem aumentando e deve ter seu primeiro ápice quando (e se) a Copa for realizada exitosamente em 2014. Provável e possivelmente, as Olimpíadas no Rio de Janeiro em 2016 também servirão como um marco de atração de outros países ao Brasil.

\section{CONSIDERAÇÕES FINAIS}

A partir do exemplo brasileiro, é possível perceber o quão relevante é o futebol nas Relações Internacionais, especificamente para o soft power. Ele não somente serve como elemento aglutinador de massas, mas também como propaganda, e carrega enorme simbolismo. Levando isso em consideração, é no mínimo curioso pensar que não se tenha abordado esse tema nessa área de estudos com a devida 
158 | InterAção

frequência.

O potencial da função do futebol como meio de soft power se faz presente no fato de que ele é um esporte mundial assistido por bilhões e praticado por centenas de milhões. As seleções nacionais são vistas como representantes quase oficiais do país, portanto, cada vez que um jogo é realizado, tem-se a impressão de que é o país todo em campo. Destarte, o esporte, em especial o futebol, afigura-se como um elemento fundamental para a criação e manutenção de laços amistosos entre as nações. Tais laços são sinais de que o soft porwer está presente, ou seja, o caminho para que os objetivos dos Estados sejam alcançados sem coerção ou trocas está assentado graças ao futebol. Portanto, conclui-se que o futebol é um instrumento primário no exercício direto e indireto do soft power, devendo os países prestarem mais atenção a esse esporte.

\section{REFERÊNCIAS}

AGUILAR, Sérgio Luiz Cruz. Uma cultura brasileira em operações de paz. In: Caderno GAPConflitos III. Contribuição brasileira às missões de paz da ONU. 1a Ed. Rio de Janeiro: Gramma, 2008.

ALLISON, Lincoln; MONNINGTON, Terry. Sport, Prestige and International Relations. Government and Opposition. v. 37, n. 1, p. 106$134,2002$.

BECK, Peter J. The relevance of the 'irrelevant': football as a missing dimension in the study of British relations with Germany. International Affairs. v. 79, n. 2, p. 389-411, 2003.

BIAZZI, Alessandro; FRANCESCHI NETO, Virgílio. Futebol e política externa brasileira: entre o político-identitário e o comercial. EFDeportes.com Revista Digital. Ano 11, n. 104, janeiro de 2007. 
InterAção | 159

Disponível em: <http://www.efdeportes.com:80/efd104/futebol-epolitica-externa-brasileira.htm>. Ultimo acesso: 27 de novembro de 2008.

BONIFACE, Pascal. Football as a factor (and a reflection) of international politics. Centre d'Etudes et de Recherches Internationales. Junho de 2002. Disponível em: <http://www.ceri-sciencespo.com/cerifr/ archive/2002.php>. Ultimo acesso em: 25 de novembro de 2008.

KENNEDY, Paul. ¿Poder duro contra poder blando?. El País. p. 8-9, 19 de fevereiro de 2005.

LARGE, David C. Nazi Games - The Olympics of 1936. Norton, W. W. \& Company, Inc, 2007.

MELISSEN, Jan. Wielding Soft Power: The New Public Diplomacy. Haia: Netherlands Institute of International Relations Clingendael, 2005. (Clingendael Diplomacy Papers No. 2)

NOYA, Javier. The symbolic power of nations. Place Branding. v. 2, n. 1, p. 53-67, janeiro de 2006.

NYE, Jr., Joseph S. Soft Power. Foreign Policy. n. 80, p. 153-171, Fall 1990

Soft power: the means to success in world politics. New York: PublicAffairs, 2004.

Think again: soft power. Foreign Policy. Fevereiro de 2006. Disponível em: <http://www.foreignpolicy.com/story/cms. php?story_id=3393>. Acesso em: 15 de novembro de 2008.

The Olympics and Chinese Soft Power. The Huffington Post.24 de agosto de 2008. Disponível em: <http://www. huffingtonpost.com/joseph-nye/the-olympics-and-chinese_b_120909. html>. Acesso em: 14 de novembro de 2008.

SHIRER, William L. The rise and fall of the Third Reich. New York, Simon \& Schuster, 1960.

SINGH, Bhartendu Kumar. China, India and the race for soft power. Institute of Peace and Conflict Studies. 29 de dezembro de 2006. Disponível em: $<$ http://www.ipcs.org/whatsNewArticle11.jsp?action= 
160 | InterAção

showView $\& k$ Value $=2186 \&$ status $=$ article $\& \bmod =b>$. Acesso em: 14 de novembro de 2008.

WANG, Jian. Localising public diplomacy: The role of sub-national actors in nation branding. Place Branding. v. 2, n. 1, p. 32-42, janeiro 2006. 